COELHO, H.E. et al. Ocorrência de feocromocitoma em adrenal com metástase no intestino e rim de um cão - relato de caso. PUBVET, Londrina, V. 5, N. 38, Ed. 185, Art. 1246, 2011.

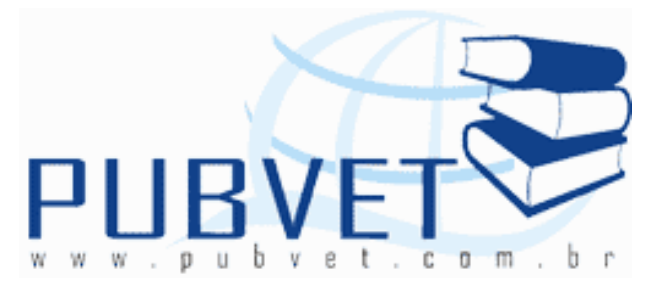

PUBVET, Publicações em Medicina Veterinária e Zootecnia.

\title{
Ocorrência de feocromocitoma em adrenal com metástase no intestino e rim de um cão - relato de caso
}

Humberto Eustáquio Coelho ${ }^{1}$, Tatiane Furtado de Carvalho ${ }^{2}$, Jéssica Beatriz Nunes ${ }^{3}$, Danielle Cristine Borges da Silva ${ }^{3}$, Hélio Alberto ${ }^{4}$, Claúdio Henrique Gonçalves Barbosa ${ }^{1}$, Rodrigo Supranzetti de Rezende ${ }^{1}$, Flávia Maria Esteves Machado $^{1}$

${ }^{1}$ Professor na Universidade de Uberaba;

${ }^{2}$ Residente de Patologia Animal na Universidade de Uberaba;

${ }^{3}$ Discente do Curso de Medicina Veterinária da Universidade de Uberaba;

${ }^{4}$ Farmacêutico e Técnico do Laboratório de Anatomia Patológica do Hospital Veterinário de Uberaba (HVU);

\section{Resumo}

O feocromocitoma é o tumor mais frequente da medular da adrenal, originado de células cromafins denominadas de feocromócitos, que ocorrem não só na medular da adrenal como também nos paragânglios do sistema nervoso simpático. É uma neoplasia rara nos cães, responsável por aproximadamente 0,01 a $0,13 \%$ dos tumores caninos, sendo ainda mais raro em gatos. Os exames laboratoriais, na suspeita de feocromocitoma, procuram comprovar a hipersecreção de catecolaminas e deve proceder a propedêutica por imagens. A pesquisa deve ser iniciada pelas dosagens basais de catecolaminas e seus metabólitos na urina e no sangue. Um cão Fox paulistinha, macho, de dez anos 
COELHO, H.E. et al. Ocorrência de feocromocitoma em adrenal com metástase no intestino e rim de um cão - relato de caso. PUBVET, Londrina, V. 5, N. 38, Ed. 185, Art. 1246, 2011.

de idade, foi encaminhado ao Hospital Veterinário de Uberaba com queixa principal de vômito, diarréia com sangue e anúria. O animal veio a óbito e encaminhado para o laboratório de Anatomia Patológica, onde foi realizada a necropsia. Apresentou uma neoplasia de aspecto gorduroso na glândula adrenal do rim direito, tendo metástase neste rim e em partes do intestino delgado.

Palavras-chave: tumor de adrenal, catecolaminas, hidropericárdio.

\title{
Occurrence of adrenal pheochromocytoma with of metastasis the gut and kidney of a dog - case report
}

\begin{abstract}
A pheochromocytoma is a tumor that occurs in the medulla of the adrenal gland often considered rare in dogs and is rare in cats. The diagnosis for this neoplasm occurs incidentally during autopsy or during surgery. When found in imaging may be treated, but not very common because the affected animals show no clinical signs evident. This study aimed to report the case of a dog with pheochromocytoma, Fox zebrafish, male, ten years old, who was referred to the Veterinary Hospital of Uberaba complaining of vomiting, bloody diarrhea and anuria. The animal came to death and in the laboratory of Pathology autopsy was performed. In macroscopic findings, the animal had greasy appearance of tumors, metastatic kidney and small intestine. Confirmation of that was made histopathologically.
\end{abstract}

Keywords: tumor of the adrenal, catecholamines, hydropericardium.

\section{INTRODUÇÃO}

Dentre os tumores da medular da adrenal, o feocromocitoma é o mais frequente, originado de células cromafins denominadas de feocromócitos, que ocorrem não só na medular da adrenal como também nos paragânglios do 
COELHO, H.E. et al. Ocorrência de feocromocitoma em adrenal com metástase no intestino e rim de um cão - relato de caso. PUBVET, Londrina, V. 5, N. 38, Ed. 185, Art. 1246, 2011.

sistema nervoso simpático, também denominado de paraganglioma (RIOS et al., 1999).

O feocromocitoma é uma neoplasia rara nos cães, responsável por aproximadamente 0,01 a $0,13 \%$ dos tumores caninos, sendo ainda mais raro em gatos. Em animais com hiperadrenocorticismo, algumas células cromafins da medula adrenal são expostas ao sangue venoso da cortical e o cortisol, nesse caso em excesso, estimula a síntese de catecolaminas e talvez promova hiperplasia ou neoplasia da medula adrenal. Nos cães, aproximadamente $50 \%$ das neoplasias são malignas e 15 a 30\% causam metástases em linfonodos, pulmão, fígado, rim, ossos, coração, baço e pâncreas (DALECK et al., 2009).

Macroscopicamente, o feocromocitoma tem uma cor castanhoavermelhada e pode ser solitário ou múltiplo, e envolve uma ou mais adrenais. A medula e o córtex adrenais circunjacentes podem sofrer compressão pelos tumores mais volumosos. Habitualmente, a encapsulação é no máximo incompleta, mas pode ocorrer alguma trabeculação no tumor. Podemos observar um pigmento castanho (lipofuscina) na periferia do tumor. Células tumorais pouco diferenciadas podem invadir os tecidos adjacentes, crescendo até a veia cava. Nesse tipo de tumor, podemos esperar pela ocorrência de metástases (JONES et al., 2000).

Os exames laboratoriais, na suspeita de feocromocitoma, procuram comprovar a hipersecreção de catecolaminas e deve proceder a propedêutica por imagens. A pesquisa deve ser iniciada pelas dosagens basais de catecolaminas e seus metabólitos na urina e no sangue (MALACHIAS et al., 2002).

A histopatologia as células neoplásicas nos feocromocitomas variam de pequena e redonda a poliédricas e grandes, similar às células medulares normais. Apresentam citoplasma abundante, levemente eosinofílico, finamente granular e frequentemente indistintos, com núcleos múltiplos e hipercromáticos (OLIVEIRA et al., 2009). As células tumorais podem estar dispostas em cordões irregulares ou conjuntos arciformes, separados por um sistema vascular abundante (JONES et al., 2000). 
COELHO, H.E. et al. Ocorrência de feocromocitoma em adrenal com metástase no intestino e rim de um cão - relato de caso. PUBVET, Londrina, V. 5, N. 38, Ed. 185, Art. 1246, 2011.

Os cães com feocromocitoma apresentam prognóstico reservado a desfavorável, uma vez que não é possível a remoção cirúrgica desses tumores em $50 \%$ ou mais dos casos, devido à invasão precoce do sistema venoso e de metástases distantes através da veia cava caudal. No entanto, pode-se conseguir um longo período de sobrevivência após a remoção cirúrgica completa de aproximadamente três anos desde que não haja metástase. A maioria dos cães é submetida à eutanásia ou morrem antes da identificação do feocromocitoma (OLIVEIRA et al., 2009).

O diagnóstico geralmente é considerado acidental e realizado durante a necropsia, ou é um achado durante o ato cirúrgico. A maior parte das manifestações clínicas produzidas é decorrente do aumento de catecolaminas circulantes ou do efeito mecânico de compressão exercido pela massa tumoral em relação aos órgãos adjacentes (PLATT et at., 1998).

O objetivo deste trabalho foi relatar um caso de feocromocitoma em cão, devido à raridade da ocorrência desta neoplasia, evidenciando as características citológicas e histopatológicas.

\section{RELATO DE CASO}

Um cão Fox paulistinha, macho, de dez anos de idade, foi encaminhado ao Hospital Veterinário de Uberaba com queixa principal de vômito, diarréia com sangue e anúria. Ao exame clínico as mucosas estavam hipocoradas, desidratado, hipotérmico, língua necrosada e presença de vômito independente da ingestão de alimento. Apresentou anemia normocítica normocrômica com presença de discreta anisocitose e policromasia. Linfopenia e aumento nos bastonetes. O exame de urina apresentava proteinúria, hematúria, bilirrubinúria e presença de cilindros granulosos. No exame de bioquímica sérica apresentou aumento de uréia, creatinina, e glicose de maneira significativa.

O animal veio a óbito e encaminhado para o laboratório de Anatomia Patológica, onde foi realizada a necropsia, encontrando: glossite ulcerativa, 
COELHO, H.E. et al. Ocorrência de feocromocitoma em adrenal com metástase no intestino e rim de um cão - relato de caso. PUBVET, Londrina, V. 5, N. 38, Ed. 185, Art. 1246, 2011.

hidroperitôneo, mucosas pálidas, edema pulmonar, nefrite crônica e hidronefrose, enfisema pulmonar e pneumonia em fase aguda de hepatização vermelha, coração dilatado e áreas de infarto no miocárdio. Apresentou uma neoplasia de aspecto gorduroso na glândula adrenal do rim direito (Figura 1), tendo metástase neste rim (Figura 2) e em partes do intestino delgado (Figura $3)$.

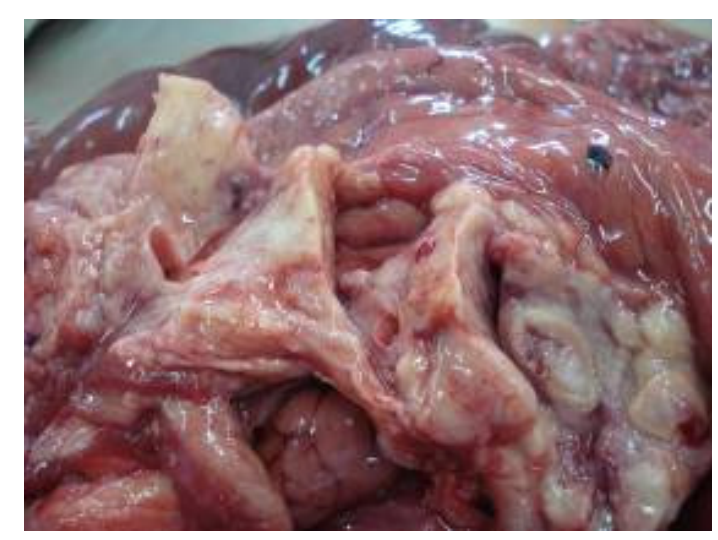

Figura 1. Glândula adrenal neoplásica de um cão, confirmado histologicamente e citologicamente como sendo um feocromocitoma.

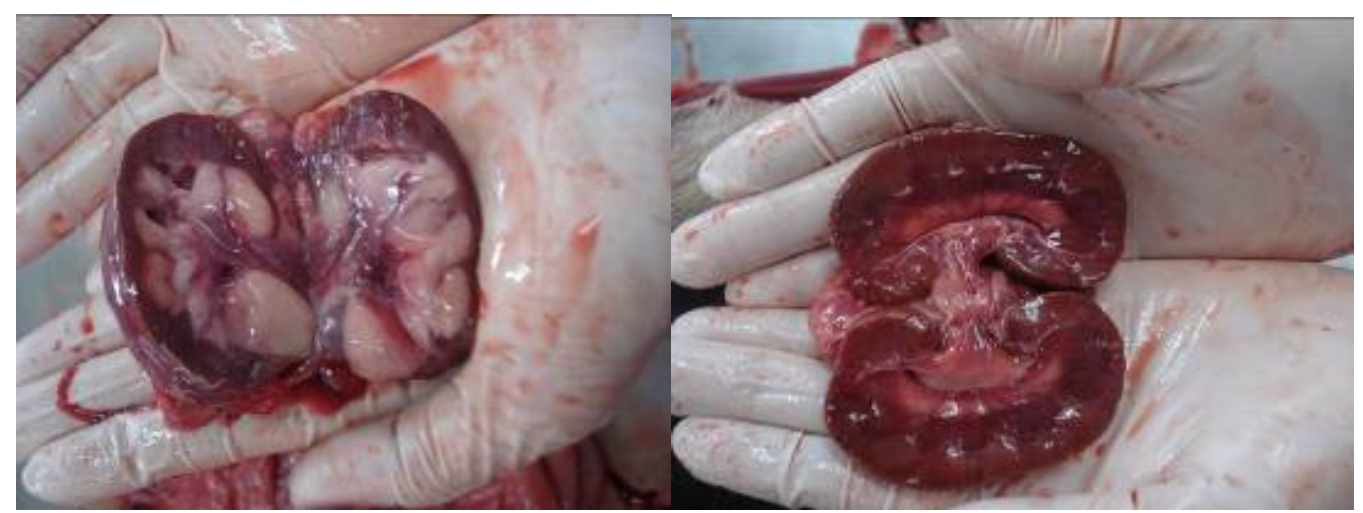

Figura 2. Á esquerda temos o rim direito, apresentando metástase do feocromocitoma em adrenal, invadindo este. Á direita temos o rim esquerdo, que não apresentou nenhum comprometimento. 
COELHO, H.E. et al. Ocorrência de feocromocitoma em adrenal com metástase no intestino e rim de um cão - relato de caso. PUBVET, Londrina, V. 5, N. 38, Ed. 185, Art. 1246, 2011.

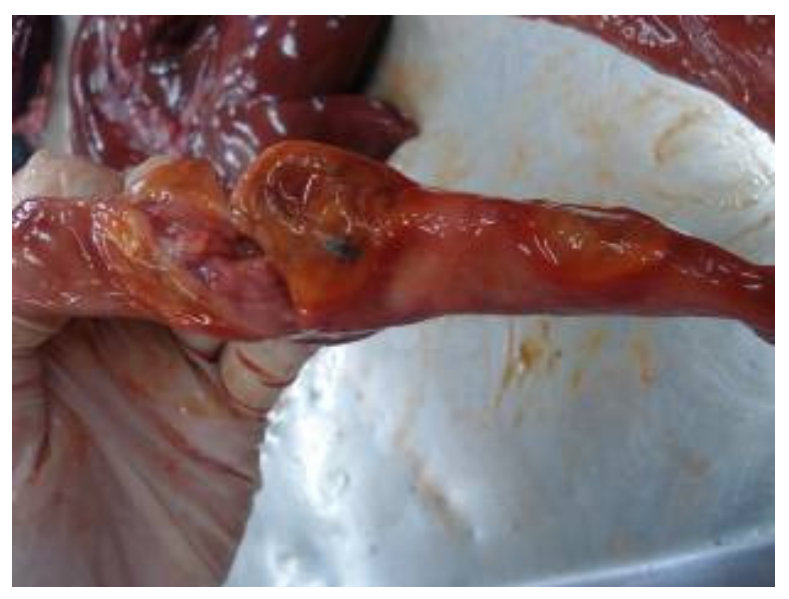

Figura 3. Presença de metástase do feocromocitoma em adrenal para o intestino delgado do cão.

Realizou-se citologia pelo método de "imprint" da amostra da glândula adrenal neoplásica, coradas com panótico rápido (Figura 4). No exame citológico foi observadas células com citoplasma azul pálido e abundante, com algumas mais coradas, com núcleos variando de formas e tamanhos, alguns ovalóides ou fusiformes e hipercromasia. Fragmentos foram coletados para histopatologia, da glândula adrenal e das áreas com metástases. No exame histopatológico (Figura 5) observou células dispostas em cordões, envoltas por estroma, com núcleos de vários tamanhos e hipercromáticos. 
COELHO, H.E. et al. Ocorrência de feocromocitoma em adrenal com metástase no intestino e rim de um cão - relato de caso. PUBVET, Londrina, V. 5, N. 38, Ed. 185, Art. 1246, 2011.

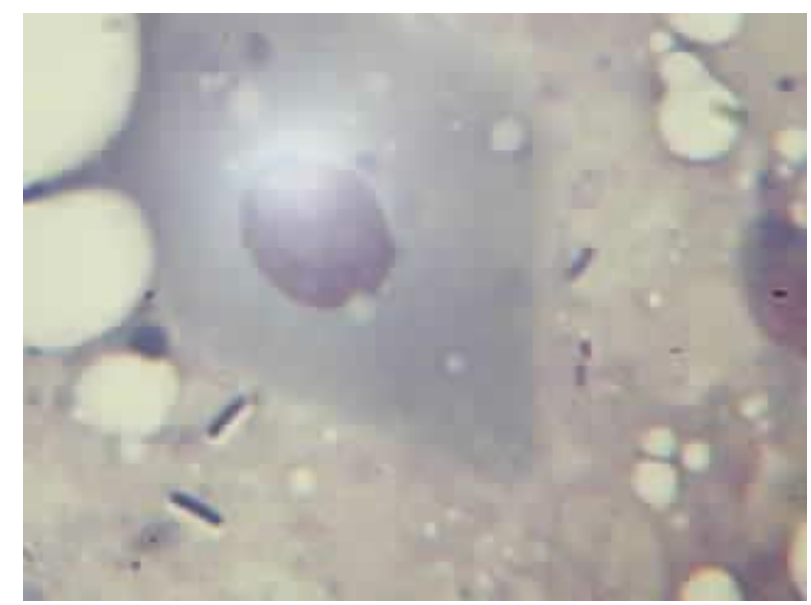

Figura 4. "Imprint" do feocromocitoma presente na glândula adrenal direita, análise citológica. A lâmina apresenta células grandes, com citoplasma abundante e núcleo arredondado (Coloração Panótico rápido, aumento de 100x).

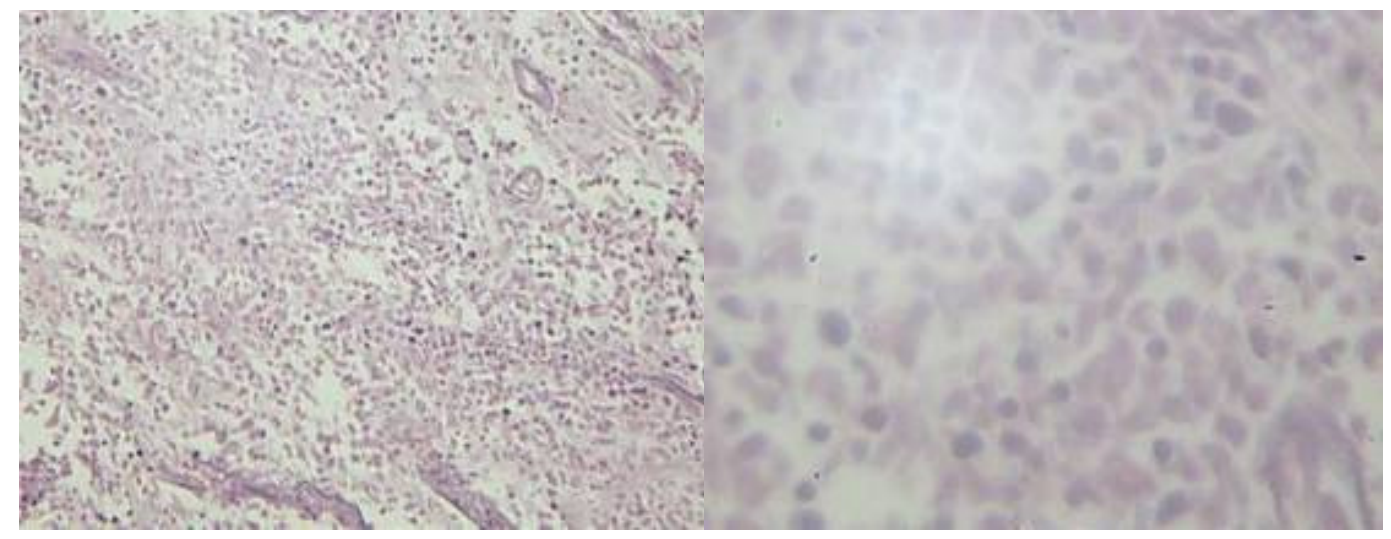

Figura 05 - Microfotografia do feocromocitoma: neoplasia da medula da adrenal. Evidenciando células com núcleos hipercromáticos e pleomórficos, poligonais de citoplasma claro e envoltas por um delgado estroma (HE, aumento 10x). Á direita observar que as células variam o tamanho, de pequenas e redondas a poliédricas e grandes, e a presença de núcleos hipercrómaticos ( $\mathrm{HE}$, aumento 40x). 
COELHO, H.E. et al. Ocorrência de feocromocitoma em adrenal com metástase no intestino e rim de um cão - relato de caso. PUBVET, Londrina, V. 5, N. 38, Ed. 185, Art. 1246, 2011.

\section{DISCUSSÃO}

Neste estudo, a neoplasia da medular da adrenal foi classificada como feocromocitoma e, de acordo com as circunstâncias de ocorrência, considerada achado incidental e de natureza espontânea (RIOS et al., 1999).

No caso estudado, não foi relatado sinais clínicos relacionados à secreção anormal de adrenalina, como a hipertensão sanguínea, responsável por alterações morfofuncional no coração, além de sudorese, anorexia e emagrecimento (SACHMAN et al., 1996).

Nos animais, acomete principalmente os cães, com manifestações clínicas de edema nos membros torácicos e pescoço, alterações cardíacas como dilatação dos ventrículos e hidropericárdio (RIOS et al., 1999). Sachman et al. (1996) comentaram que esse tipo de neoplasia é rara em cães e pode causar dispnéia, taquicardia, tremores, irritabilidade, poliúria, polidipsia, anorexia, dentre outros.

Um estudo recente de 61 casos de feocromocitomas em cães determinou que se desenvolva nos de meia-idade a velhos (DALECK et al., 2009), concordando com este relato, ocorrendo em um cão de dez anos de idade.

Daleck et al. (2009) realizou um estudo com 50 animais afetados, 52\% apresentavam invasão local pelo tumor, 12\% tinham metástases em linfonodos regionais e $24 \%$ tinham metástases a distância (isto é, pulmão, fígado, baço e ossos) o que foi observado também por Maher e Mcniel (1997). Nesse caso clínico a metástase ocorreu para o intestino e para o rim adjacente a glândula neoplásica.

Os tumores apresentam tamanhos variados, mas um quarto é grande, chegando a ser palpável, causando compreensão de órgãos próximos. Podem invadir tecidos vizinhos, principalmente o rim e a veia cava caudal, formando trombos extensos de células tumorais, que podem ser detectados por radiografias abdominais. (DALECK et al., 2009). 
COELHO, H.E. et al. Ocorrência de feocromocitoma em adrenal com metástase no intestino e rim de um cão - relato de caso. PUBVET, Londrina, V. 5, N. 38, Ed. 185, Art. 1246, 2011.

Em contraste com os relatos no homem, um grande número de cães com feocromocitoma (15 a 38\% dos casos) apresentam invasão das estruturas adjacentes, particularmente da veia cava caudal (PLATT et al., 1998).

A artéria renal direita apresentava desvio do trajeto e compressão mecânica exercida pelas massas tumorais, sem invasão intraluminal. Além disso, o rim direito encontrava-se deformado pela compressão mecânica da massa tumoral e pela invasão metastática do mesmo.

Em estudo publicado na literatura internacional (MAHER, McNIEL, 1997) observou-se que $25 \%$ dos casos de feocromocitomas apresentavam massas abdominais palpáveis. Segundo a literatura, é frequente observar-se aumento das dimensões cardíacas, congestão pulmonar ou até mesmo edema nas radiografias torácicas (GILSON et al., 1994), o que condiz com esse relato que observou na necropsia a presença de edema pulmonar e dilatação cardíaca.

Já nas radiografias de abdome relata-se a presença de massas em cerca de 30 a 50\% dos casos (MAHER, McNIEL, 1997). As neoplasias adrenais no lado esquerdo são mais facilmente detectáveis ao exame radiográfico do que do lado direito (PLATT et al., 1998), embora um estudo (GILSON et al., 1994) afirme que as neoplasias adrenais do lado direito sejam mais frequentes, como foi diagnosticado no nosso paciente, que apresentou o desenvolvimento da neoplasia na adrenal direita.

Com um feocromocitoma funcional, os níveis de catecolaminas no sangue encontram-se aumentados e podem ser detectáveis, porém a determinação destes índices é difícil e de alto custo. As concentrações urinárias das catecolaminas e metabólitos geralmente são consideradas mais exeqüíveis, porém igualmente custosas. A literatura recomenda que seja realizada amostragem de urina produzida durante 24 horas, porém os resultados nem sempre são considerados conclusivos (PLATT et al., 1998).

Os achados bioquímicos e hematológicos foram inespecíficos e compatíveis com aqueles relatados em literatura (GILSON et al., 1994). Citase que uma alteração comum da bioquímica sérica nos casos de feocromocitoma é o aumento da ALT e da AST, devido à presença de 
COELHO, H.E. et al. Ocorrência de feocromocitoma em adrenal com metástase no intestino e rim de um cão - relato de caso. PUBVET, Londrina, V. 5, N. 38, Ed. 185, Art. 1246, 2011.

enfermidades concomitantes, como o diabetes, o hiperadrenocorticismo e hepatopatias (BARTHEZ et al., 1997). No animal deste relato, o aumento do índice de ALT pode estar relacionado à presença de uma hepatopatia secundária à hipertensão e uma cardiopatia.

O aumento da uréia, creatinina, presença de glossite ulcerativa, e clinicamente a presença de vômitos caracteriza uma quadro de uremia. A uremia é a síndrome tóxica polissistêmica que resulta de uma função renal anormal em animais com azotemia, e ocorre simultaneamente com uma quantidade aumentada de constituintes urinários no sangue (OLIVEIRA, 2004).

Para ETTINGER (2004) a uremia é o estado clínico para qual, todas as doenças renais generalizadas e progressivas no final se convergem, e os sinais associados são mais semelhantes. A uremia resulta da retenção de substâncias normalmente removidas por rins saudáveis. O aporte de precursores de substâncias nitrogenadas por meio do alimento também contribui para os sinais de uremia, assim como distúrbios na homeostase hormonal e enzimática.

Náuseas e vômitos são manifestações da insuficiência renal crônica e resultam de um número de fatores: estimulação da zona quimioreceptora pelas toxinas urêmicas, gastrite que pode ser desenvolvida como resultado dos efeitos diretos das toxinas urêmicas e do aumento das concentrações de gastrina, levando a uma produção excessiva de ácido gástrico e liberação de histamina a partir dos monócitos na produção de amônia a partir da uréia (BROVIDA et al., 2004).

O vômito pode ser uma queixa frequente nos cães urêmicos do que nos gatos. Apesar disso, o vômito é encontrado em um quarto a um terço dos gatos com sinais clínicos de uremia (ETTINGER, 2004). BICHARD (2003) descreveu que letargia, anorexia e perda de peso constituem sinais inespecíficos e que ocorrem frequentemente. Sinais gastrintestinais, tais como: inapetência, vômito e diarréia, ocorrem em pacientes urêmicos, podendo também ser observado ulcerações orais, que é uma manifestação da síndrome urêmica e em alguns casos pode haver necrose das laterais da língua. 
COELHO, H.E. et al. Ocorrência de feocromocitoma em adrenal com metástase no intestino e rim de um cão - relato de caso. PUBVET, Londrina, V. 5, N. 38, Ed. 185, Art. 1246, 2011.

Acredita-se que estas lesões são o resultado da degradação bacteriana da uréia para formar amônia, o que foi observado no animal à presença de necrose em áreas da língua.

No exame de urina foi observada a presença de cilindros, os cilindros são estruturas cilíndricas formadas dentro de lumens dos túbulos renais a partir de microproteínas. Numerosos cilindros na urina sugerem doença ativa tubular, que podem ser aguda ou crônica e poucos a muitos em nefropatia aguda (BROVIDA et al., 2004).

A eritropoietina é sintetizada pelos rins e sua função é atuar como um fator para a produção de hemácias. Essa síntese é diminuída secundariamente à redução da massa renal funcional, embora também outros fatores não discutidos também possam suprimir esta síntese. A DRC pode também ter efeitos adversos na função da eritropoietina e o aumento da proteólise do plasma pode mais adiante reduzir as concentrações de eritropoietina. Com tudo isso, o resultado final é uma anemia (ANDRADE, 1997), como observado neste relato, a presença de anemia normocítica normocrômica, que é evidenciada clinicamente pelas mucosas hipocoradas. Para FRASES (1991) a insuficiência renal crônica tem uma presença evidente de uma anemia não regenerativa.

\section{CONCLUSÃO}

Apesar do feocromocitoma ser considerado uma neoplasia de ocorrência incomum, o presente relato demonstrou a importância de incluir essa doença na lista de dignósticos diferenciais de distúrbios cardiovasculares. Os sinais clínicos podem ser associados com exames de imagens, que possibilita um diagnóstico ainda com o animal vivo, evitando posteriores metástases e que o diagnóstico ocorra acidentalmente na necropsia. 


\section{REFERÊNCIAS}

ANDRADE, S.F. Manual de Terapia Veterinário: Terapêutica do Sistema Renal, São Paulo: Rocca, 1997.

BARTHEZ, P. Y.; MARKS, S. L.; WOO, J.; FELDMAN, E. C.; MATTEUCCI, M. Pheochromocytoma in dogs: 61 cases (1984-1995). Journal of Veterinary Internal Medicine, v. 5, n. 11, p. 272-278, 1997.

BICHARD, J S. Manual Saunders: Clínica de Pequenos Animais: 2. ed. SãoPaulo: Rocca, 2003.

BROVIDA, C. et al. Revista Foccus: Diagnóstico Precoce da Insuficiência Renal Crônica, ed. Especial. Royal Canin (Waltham), 2004. 7

CARVALHO, Cibele Figueira et al. Feocromocitoma em cão: nota prévia. Braz. J. Vet. Res. Anim. Sci. [online]. 2004, vol.41, n.2, pp. 113-116.

DALECK, C.R.; NARDI, A.B.; RODASKI, S. Oncologia em cães e gatos. Roca, 2009.

ETIINGER, J. S.; FELDMAN, E. C. Tratado de Medicina Interna Veterinária: vol 2, Insuficiência Renal Crônica, 5 ed. Rio de Janeiro: Guanabara Koogan, 2004.

FRASES, C. M. Manual Merk de Veterinária: Sistema Urinário. 6 ed. São Paulo: Roca, 1991.

GILSON, S. D.; WITHROW, S. J.; WHEELER, S. L.; TWEDT, D. C. Pheochromocytoma in 50 dogs. Journal of Veterinary Internal Medicine, v. 3, n. 8, p.228-232, 1994.

JONES, T. C.; HUNT, R. D.; KING, N. W. Glândulas endócrinas. In: Patologia Veterinária. 6. ed. São Paulo: Manole, 2000.

MAHER, E. R. Jr.; McNIEL, E. A. Pheochromocytoma in dogs and cats. Veterinary Clinics of North America - Small Animal Practice, v. 2, n. 27, p. 359-380, 1997.

MALACHIAS, M. V. B. Feocromocitoma - diagnóstico e tratamento. Revista Brasileira Hipertensão, 2002.

OLIVEIRA, Krishna Duro de. Feocromocitoma e carcinoma adrenocortical associados à hipertensão e cirrose em cão - Revisão de literatura e relato de caso. Informativo da Associação Brasileira de Oncologia Veterinária, 2009.

De OLIVEIRA, S. T., Alterações de Compostos Nitrogenados Não-Proteícos em Cães e Gatos. 2004. 17 f. Seminário do Programa de Pós-graduação em Ciências Veterinárias Universidade Federal do Rio Grande do Sul - UFRGS.

PEREIRA, W.L.A.; SILVA, A.W.C. e PINTO, M.N.. Feocromocitoma em bovinos de abate: relatos de casos. Arq. Bras. Med. Vet. Zootec. [online]. 2007, vol.59, n.2, pp. 301-305.

PLATT, S. R.; SHEPPARD, B. J.; GRAHAM, J.; UHL, E. W.; MEEKS, J.; CLEMMONS, R. M. Pheochromocytoma in the vertebral canal of two dogs. Journal of American Animal Hospital Association, v. 5, n. 34, p. 365-371, 1998.

RIOS, A. A.M.; AGUILAR, B.J.; MENDEZ, A.R.E. Feocromocitoma. Informe de um caso clínico. Rev. AMMVEPE, v.10, p.90-92, 1999. 
ROSSATO, C.K.; MAIER, E. M.; PETERS, G. B. Feocromocitoma maligno em um canino Relato de caso. $35^{\circ}$ Congresso Brasileiro de Medicina Veterinária, 2008.

SACHMAN, J.E.; ADAMS, W.H.; SIMS, M.H. Feocromocitoma em cães. Pet. Vet., v.1, 1996. 